\title{
Lower gastrointestinal bleeding and ischemic colitis
}

\author{
Jamie R Newman BA MD, Mary Anne Cooper MSc MD FRCPC
}

JR Newman, MA Cooper. Lower gastrointestinal bleeding and ischemic colitis. Can J Gastroenterol 2002;16(9):597-600.

OBJECTIVE: To compare the incidence and clinical characteristics of lower gastrointestinal (LGI) bleeding due to ischemic colitis with those with LGI bleeding of other causes.

METHODS: A chart review was performed of patients admitted with LGI bleeding to Sunnybrook and Women's College Health Sciences Centre, Toronto, Ontario, between July 1, 1997 and January 31, 2000.

RESULTS: Of 124 patients with LGI bleeding, 24 cases were due to ischemic colitis, 62 to diverticulosis, 11 to inflammatory bowel disease (IBD) and 27 to all other causes ('others'). The average ages of patients in each group were 66.5, 76.5, 40.5 and 77.5 years, respectively. Patients with ischemic colitis were statistically younger than those with diverticular bleeding and 'others'. Patients with IBD were younger than those in the other three groups. The only statistical difference for vascular disease risks was hypertension, because of its absence from the IBD group. Three patients with ischemic colitis underwent blood transfusions, while 23 with diverticulosis, 15 'others' and none with IBD received blood. Three patients with ischemic colitis and one patient from the 'others' group died. More women (75) than men (49) had LGI bleeding - in total and within each subgroup. Of women with LGI bleeding, many more with ischemic colitis $(44.4 \%)$ than with diverticulosis $(3.0 \%)$, IBD (0\%) or 'others' (5.6\%) were taking estrogen.

CONCLUSIONS: Ischemic colitis was the second most common cause of LGI bleeding. LGI bleeding from all causes was more common in women than in men. Many more women in the ischemic colitis group than in the other groups were using estrogen therapy.

Key Words: Estrogen therapy; Ischemic colitis; Lower gastrointestinal bleeding

\section{Hémorragies digestives basses et colite ischémique}

OBJECTIF : Comparer l'incidence et les caractéristiques cliniques des hémorragies digestives basses (HDB) dues à la colite ischémique aux autres HDB dues à d'autres causes.

MÉTHODE : Nous avons passé en revue les dossiers des patients admis au Sunnybrook and Women's College Health Sciences Centre, à Toronto,

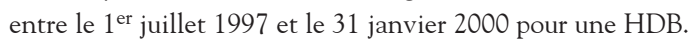

RÉSULTATS : Sur 124 patients hospitalisés pour une HDB, 24 cas étaient dus à une colite ischémique, 62 à une diverticulose, 11 à une maladie inflammatoire de l'intestin (MII) et 27 à d'autres causes ( " autres »). Lâge moyen des patients dans chacun des groupes était de 66,5; 76,5; 40,5 et 77,5 ans respectivement. Les patients souffrant d'une colite ischémique étaient statistiquement plus jeunes que ceux présentant une hémorragie due à une diverticulose ou à d'autres causes et les patients atteints d'une MII étaient plus jeunes que ceux des trois autres groupes. La seule différence statistique quant aux risques de maladie vasculaire était l'hypertension en raison de son absence dans le groupe des MII. Trois patients souffrant d'une colite ischémique ont reçu des transfusions de sang contre 23 pour la diverticulose, 15 pour les « autres » causes et aucun pour les MII. Trois patients dans le groupe de la colite ischémique et un patient dans le groupe « autres» sont morts. Plus de femmes (75) que d'hommes (49) ont présenté une HDB, et ce, dans l'ensemble du groupe et dans chacun des sous-groupes. Parmi celles-ci, beaucoup plus ayant à l'origine une colite ischémique (44,4\%) qu'une diverticulose (3,0 \%), une MII (0 \%) ou d'« autres » causes $(5,6 \%)$ prenaient des oestrogènes.

CONCLUSIONS : La colite ischémique s'est avérée la deuxième cause d'HDB. Les femmes ont été plus souvent touchées par ces hémorragies, toutes causes confondues, que les hommes. Enfin, beaucoup plus de femmes dans le groupe de la colite ischémique faisaient usage d'oestrogènes que celles dans les autres groupes.

Division of Gastroenterology, Sunnybrook and Women's College Health Sciences Centre, University of Toronto, Toronto, Ontario

Correspondence and reprints: Dr Mary Anne Cooper, Sunnybrook and Women's College Health Sciences Centre, 2075 Bayview Avenue, H-wing,

Suite HG64, Toronto, Ontario M4N 3M5. Telephone 416-480-6799, fax 416-480-5977, e-mail maryanne.cooper@swchsc.on.ca

Received for publication February 11, 2002. Accepted July 9, 2002 
$\mathrm{T}$ he differential diagnoses for lower gastrointestinal (LGI) bleeding include diverticulosis, angiodysplasia, colitis and neoplasm. Ischemic colitis is often overlooked, yet recent findings suggest that ischemic colitis may be as common as other causes, resulting in up to one in 2000 hospitalizations and one in 100 flexible sigmoidoscopies or colonoscopies (1). It is the most common vascular disorder of the intestinal tract in patients over 60 years of age (2). During the ischemic period, damage is mediated by hypoxia, followed by reperfusion injury when blood flow returns (2). It is usually a segmental process, with approximately $54 \%$ of cases involving the 'watershed' areas of the splenic flexure and/or descending colon (3). The usual presentation is one of sudden onset of left lower quadrant pain followed by the passage of bright red blood per rectum. Colonoscopy is the diagnostic modality of choice, usually showing petechial hemorrhage, friability and ulceration (4). It also allows confirmatory biopsies to be obtained.

It was our clinical impression that ischemic colitis was a common cause of LGI bleeding in patients at our centre. In the present study, therefore, we compared the occurrence, demographics and clinical features of patients admitted with LGI bleeding due to ischemic colitis with those of patients who presented with LGI bleeding due to other causes.

\section{PATIENTS AND METHODS}

A retrospective computer search was performed on patients admitted to Sunnybrook and Women's College Health Sciences Centre, Sunnybrook Campus, Toronto, Ontario, a large tertiary care centre, between July 1, 1997 and January 31, 2000. To identify patients admitted with LGI bleeding, diagnostic codes for the following conditions were used: gastrointestinal bleeding, melena, ischemic colitis, segmental colitis, angiodysplasia, diverticulosis, diverticular bleed, rectal bleed, colitis, Crohn's disease/colitis and ulcerative colitis. Of the patients identified, only those admitted with LGI bleeding as the primary diagnosis (as verified by a review of the chart) were considered further. Data regarding age, sex, disease type, vascular disease risk factors (coronary artery disease, peripheral vascular disease, smoking history, diabetes mellitus and hypertension), medications (nonsteroidal anti-inflammatory drugs, warfarin, estrogen and progestins) and outcomes were recorded.

\section{RESULTS}

By using the diagnostic codes for gastrointestinal bleeding, melena, ischemic colitis, segmental colitis, angiodysplasia, diverticulosis, diverticular bleeding, rectal bleeding, colitis, Crohn's disease/colitis and ulcerative colitis, 470 patients were identified within the defined period of time. One hundred twenty-four of these patients were admitted with LGI bleeding. The most common cause of bleeding was diverticulosis, occurring in $62(50.0 \%)$ patients. The next most common cause of bleeding was ischemic colitis in 24 (19.4\%) patients, followed by inflammatory bowel disease (IBD) in $11(8.9 \%)$ and other causes in 27 (21.8\%). The latter cate- gory ('others') included neoplasm $(\mathrm{n}=5)$, angiodysplasia $(n=3)$, radiation proctitis $(n=3)$, infectious colitis $(n=2)$ and 'not diagnosed' $(n=14)$. (Patients in the latter category were grouped together because of the small numbers in each group. It was assumed that the patients 'not diagnosed' likely had LGI bleeding due to a variety of causes.)

The average age of all patients presenting with LGI bleeding was $71.6 \pm 16.3$ years. Those with diverticular bleeding and 'others' were the oldest, with average ages at presentation of $76.5 \pm 11.4$ years and $77.5 \pm 14.1$ years, respectively. They were significantly older than those with ischemic colitis, who presented at $66.5 \pm 14.7$ years $(\mathrm{P}<0.05)$. The IBD patients were significantly younger than the other three groups, presenting at an average age of $40.5 \pm 9.1$ years.

Risk factors for vascular disease (smoking, diabetes mellitus and hypertension) and personal histories of coronary artery disease and peripheral vascular disease were obtained. None of these risk factors was present in the patients with IBD. The presence of peripheral vascular disease was uncommon in all groups. The only statistical significance in all of these factors was in the incidence of hypertension, and this difference was due solely to its absence from the IBD group $(\mathrm{P}<0.002)$. No statistical significance in the occurrence of LGI bleeding was observed with the use of nonsteroidal anti-inflammatory drugs or warfarin (data not shown).

The outcomes for patients were recorded as the number of patients requiring transfusion, the number of units of packed red blood cells given and the number of deaths. Only three patients with ischemic colitis underwent blood transfusion, receiving an average of 2.3 units of packed red blood cells per patient. Twenty-three patients with diverticular bleeding underwent blood transfusion and received an average of 4.9 units per patient, while 15 from the 'other' category received an average of 3.1 units per patient. No patient with IBD underwent blood transfusion and none from this group died. Three patients with ischemic colitis, one from the 'other' category and none from the diverticular bleed group died. The numbers in these subgroups were too small to allow statistical analyses.

Many more women $(n=75,60.5 \%)$ than men $(n=49$, $39.5 \%)$ experienced LGI bleeding $(\mathrm{P}<0.05)$. No one group accounted for this difference because there were more women than men in each group. Of the women in the ischemic colitis group, $44.4 \%$ (eight of 18) were using estrogen therapy, in the form of either hormone replacement therapy (six of eight) or oral contraception (two of eight). In comparison, $5.6 \%$ (one of 18 ) of 'others', 3.0\% (one of 33 ) in the diverticular group and $0 \%$ with IBD were using estrogen therapy. This difference was highly significantly different $(\mathrm{P}=0.00009)$.

\section{DISCUSSION}

Common causes of LGI bleeding are reported to be diverticulosis, angiodysplasia and cancer (5). Despite that ischemic colitis is often not listed as a differential diagnosis 
of LGI bleeding, it was second only to diverticulosis as a cause of bleeding in the population that we studied. Conversely, while angiodysplasia is often listed as a common cause of LGI bleeding, particularly in older patients (6), only three cases $(2.4 \%)$ were identified in this series of patients, whose average age, excluding IBD patients, was 71.6 years.

In the present study, patients with ischemic colitis were younger (66.5 years) than those with diverticular bleeding (76.5 years) or bleeding from 'other' causes ( 77.5 years). We did not detect an increased incidence of coronary artery disease, peripheral vascular disease or risk factors for these conditions in patients with ischemic colitis. This result is different from data reported elsewhere, which has suggested that ischemic colitis typically occurs in elderly patients with comorbidities that include vascular disease (7).

Large quantities of blood loss are unusual in patients with ischemic colitis because the ischemic segment usually stops bleeding spontaneously (8). Our data were consistent with this observation; only three patients with ischemic colitis required a blood transfusion (average of 2.3 units each). This was lower than the transfusion requirements for patients with diverticular and other causes (although a statistical significance was not shown).

Despite the lack of risk factors for vascular disease, the lack of personal histories of coronary artery disease or peripheral vascular disease, and fewer patients needing a blood transfusion, the highest death rate was seen in the ischemic colitis group. The numbers in these subgroups were quite small and precluded statistical analyses; however, they suggest that factors other than vascular disease or the magnitude of the bleeding may be important in the clinical outcome of patients with ischemic colitis.

Most patients with LGI bleeding from all causes were women $(60.5 \%)$, which is different from what has been reported by some $(9,10)$. This difference could not be accounted for by any one group because more women than men experienced LGI bleeding in each subgroup.

The most striking result of this study was that significantly more women in the ischemic colitis group (44.4\%) than in the other subgroups $(0 \%$ to $5.6 \%)(\mathrm{P}=0.00009)$ were found to be using estrogen as either hormone replacement therapy or oral contraception. Other investigators have linked oral contraceptive use to ischemic colitis in young women (11-13). Oral contraceptives have been associated with an increased incidence of thromboembolic events (14), although it is not known exactly how this may occur. There may be a hypercoagulable state in which patients taking oral contraceptives acquire resistance to activated protein $\mathrm{C}$ (11). A dysfunctional activated protein $\mathrm{C}$ or a deficiency of this protein does not allow for the inactivation of plasma coagulation factors, resulting in a hypercoagulable state. The evidence for an association between estrogen use, and ischemic colitis and thromboembolic events exists mainly in the form of case reports and small series. In one case, a young woman with ischemic colitis was found to have activated protein $\mathrm{C}$ resistance while tak- ing an oral contraceptive (11). When the oral contraceptive was discontinued, the activated protein $\mathrm{C}$ resistance resolved. In one of the larger series of patients, Deana and Dean (12) found that $59 \%$ of young women with ischemic colitis used oral contraceptives or were taking hormone replacement therapy. The 1988 national average of women aged 15 to 44 years who used oral contraceptives was $18.5 \%$. The authors concluded from their data that, before the fifth decade of life, ischemic colitis was a disorder predominantly found in women and that there was a statistical association between ischemic colitis and oral contraceptive use. Rosing et al (13) reported that women using oral contraceptives who were heterozygous for factor $\mathrm{V}$ Leiden defect had a 30 to 50 times increased risk of having a thromboembolic event and that this approached the risk of those who were homozygous for the defect (80-fold increase). These numbers compared with a sevenfold increase in those with heterozygosity for factor V Leiden defect and not using oral contraception and a seven- to eightfold increase in non-carriers of factor $\mathrm{V}$ Leiden who used oral contraception. More recently, Koutroubakis et al (15) reported that approximately $72 \%$ of patients with ischemic colitis had either a congenital or acquired thrombophilic state. This study was one of the first to retrospectively review patients with ischemic colitis combined with a comprehensive thrombophilic screening process. Patients with ischemic colitis were compared with matched healthy controls and patients. The prevalence of thrombotic risk factors such as protein C deficiency, antiphospholipid antibody and factor $\mathrm{V}$ Leiden defect was measured. The study reported that the prevalence of thrombotic risk factors was significantly higher in those with ischemic colitis than in both control groups. The most significant associations observed were antiphospholipid antibody and factor $\mathrm{V}$ Leiden defect. Because of all these conditions and interactions, it has been suggested that women who experience a thrombotic event while using estrogen therapy should be screened for hereditary and acquired thrombotic mutations or defects (16).

Interestingly, in our study, none of the six women in the IBD group was on estrogen therapy (as either oral contraception or hormone replacement therapy). We reviewed these cases further to try to explain this finding. Four of the six women, ages 25 to 45 years, had documented reasons why they did not need to be on estrogen therapy as birth control (infertility [ $\mathrm{n}=2]$, hysterectomy $[\mathrm{n}=1]$ and planning a pregnancy $[\mathrm{n}=1])$. We could not establish a specific reason why two women, ages 43 and 59 years of age, might not have been taking estrogen. It is possible that there was a deficiency in the chart documentation, which is an error inherent to the design of this type of study but exists for all of the groups.

This study was a single-centre, retrospective chart review that suffers from the flaws of all studies of this design, such as referral bias, reliance on accuracy of diagnostic codes and possible incomplete health records. As well, this study, in particular, sought to evaluate the charac- 
teristics of patients presenting with LGI bleeding and thereby limited the scope of patients with ischemic colitis to those who might have had more significant disease. Nevertheless, its strength is that it clearly has demonstrated a highly statistically significant association between ischemic colitis presenting with LGI bleeding and the use of estrogen, as either hormone replacement therapy or oral contraception, in women. It certainly points to the need for further investigation into this association.

\section{CONCLUSIONS}

Ischemic colitis was found to be a common cause of LGI bleeding, second only to diverticular bleeding. Many more women than men experienced LGI bleeding from all causes. An association between ischemic colitis and other vascular disease was not seen. There was a highly significant increase in the number of women with ischemic colitis who used estrogen compared with women in the other groups. Further work is necessary to investigate the issue of estrogen use and its association with ischemic colitis, with particular attention to possible reversible activated protein $\mathrm{C}$ resistance as a cause for a hypercoaguable state.

\section{REFERENCES}

1. Charles M, Lawrence J. Colon ischemia: unusual aspects. Clin Perspect Gastroenterol 2000;3:315-26.

2. Leung F. Ischemic colitis. In: Targan SR, Shanahan F, eds. Inflammatory Bowel Disease: From Bench to Bedside. Baltimore: Williams and Wilkins, 1994:721-33.
3. Brandt LJ, Smithline AE. Ischemic lesions of the bowel. In: Feldman M, Scharschmldt BF, Sleisenger MH, eds. Gastrointestinal and Liver Disease, 6th edn. Philadelphia: WB Saunders, 1998:2000-2.

4. Gandhi SK, Hanson MM, Vernava AM, Kaminski DL, Longo WE. Ischemic colitis. Dis Colon Rectum 1996;39:88-100.

5. Zuccaro G. Gastrointestinal hemorrhage. In: Andreoli TE, Carpenter CCJ, Griggs RC, Loscalzo J, eds. Essentials of Medicine, 5th edn. Philadelphia: WB Saunders, 2001:306-9.

6. Farrell JJ, Friedman LS. Gastrointestinal bleeding in older people. Gastroenterol Clin North Am 2000;29:1-36.

7. Habu Y, Tahashi Y, Kiyota K, et al. Reevaluation of clinical features of ischemic colitis: Analysis of 68 consecutive cases diagnosed by early colonoscopy. Scand J Gastroenterol 1996;31:881-6.

8. Newman G. Gastrointestinal bleeding. In: Fishman MC, Hoffman AR, Klausner RD, Thaler MS, eds. Medicine, 4th edn. Philadelphia: Lippincott-Raven, 1996:239-41.

9. Toursarkissian B, Thompson RW. Ischemic colitis. Surg Clin North Am 1997;77:461-70.

10. Fallah MA. Acute gastrointestinal bleeding. Med Clin North Am 2000;84:1183-208.

11. Mann DE Jr, Kessel ER, Mullins DL, Lottenberg R. Ischemic colitis and acquired resistance to activated protein $\mathrm{C}$ in a women using oral contraceptives. Am J Gastroenterol 1998;93:1960-2.

12. Deana DG, Dean PJ. Reversible ischemic colitis in young women: association with oral contraceptive use. Am J Surg Pathol 1995; 19:454-62.

13. Rosing J, Tans G, Nicolaes GAF, et al. Oral contraceptives and venous thrombosis: Different sensitivities to activated protein $\mathrm{C}$ in women using second-and third-generation oral contraceptives. Br J Haematol 1997;97:233-8.

14. Vandenbroucke JP, Rosing J, Bloemenkamp KW, et al. Oral contraceptives and the risk of venous thrombosis. N Engl J Med 2001;344:1527-35.

15. Koutroubakis IE, Sfiridaki A, Theodoropoulou A, Kouroumalis EA. Role of acquired and hereditary thrombotic risk factors in colon ischemia of ambulatory patients. Gastroenterology 2001;121:561-5.

16. Selby R, Geerts WH. Venous thromboembolism: risk factors and prophylaxis. Semin Respir Crit Care Med 2000;21:493-501. 


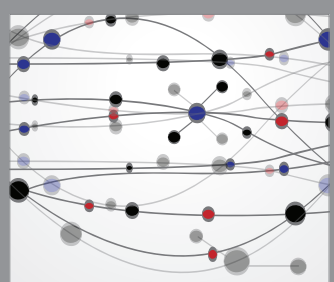

The Scientific World Journal
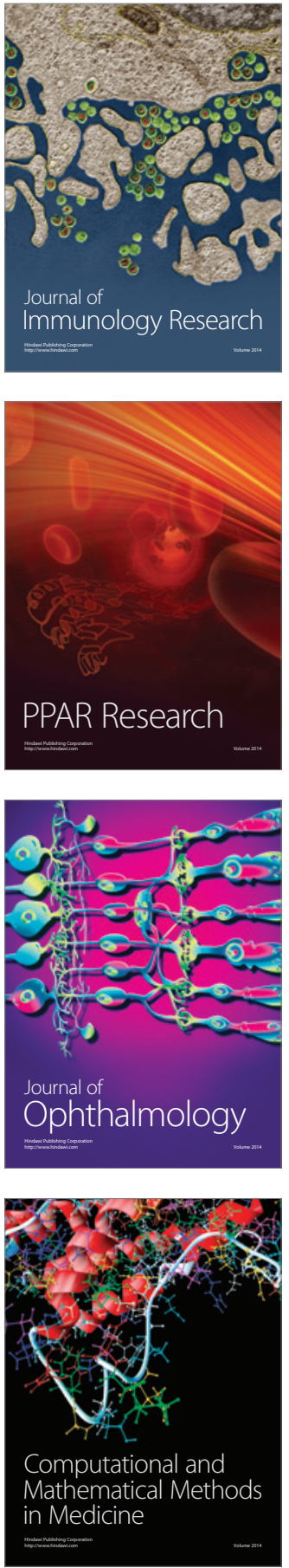

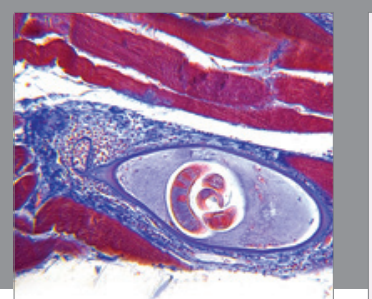

Gastroenterology Research and Practice

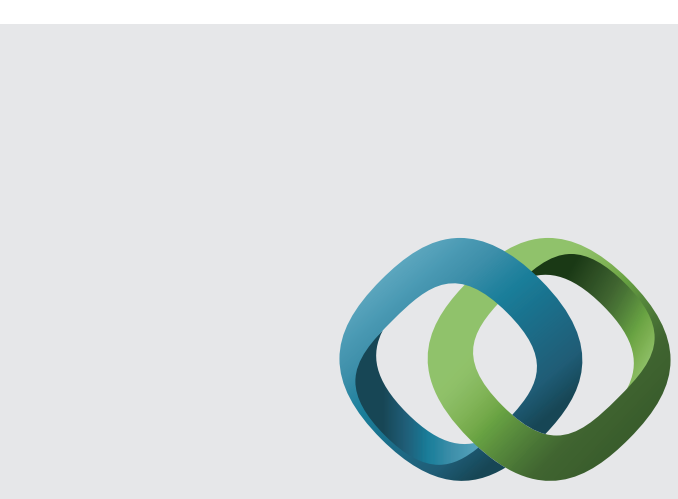

\section{Hindawi}

Submit your manuscripts at

http://www.hindawi.com
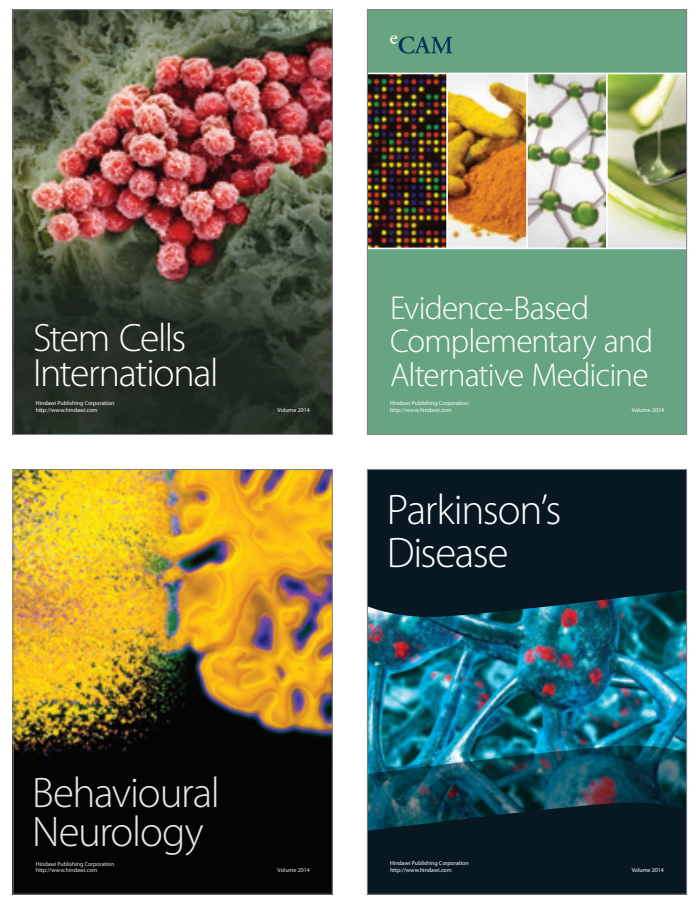
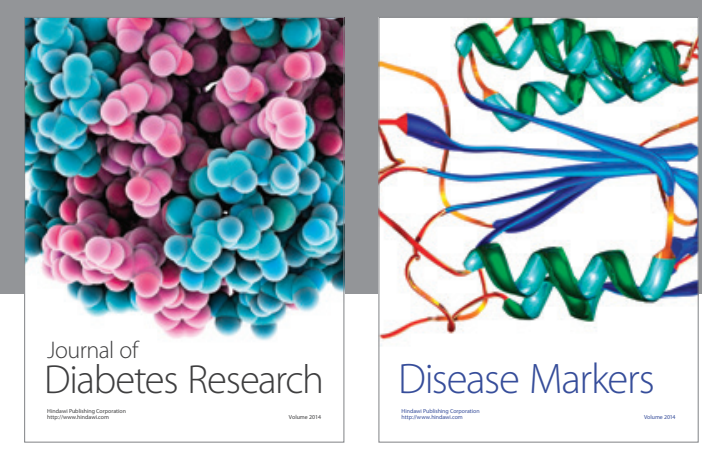

Disease Markers
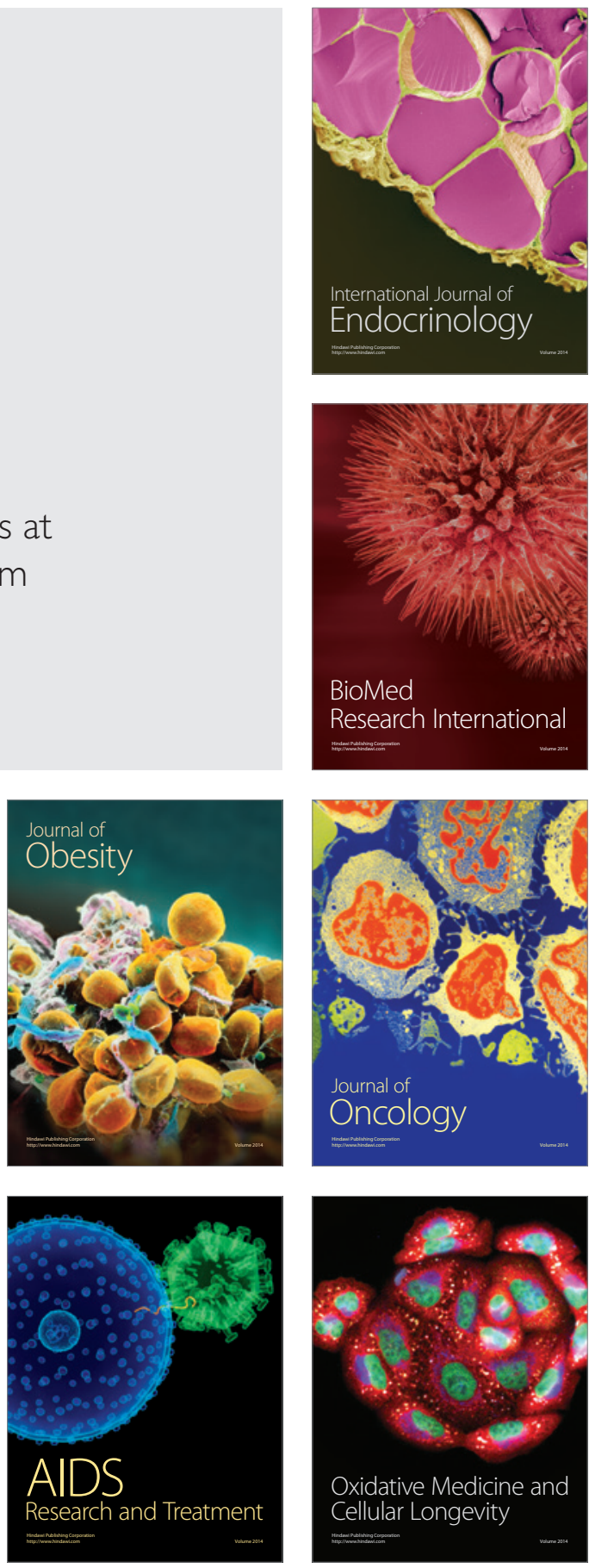